\title{
Helping the Hong Kong Medical Journal and Hong Kong to advance their impact on medical practice
}

Hong Kong Med J 2016;22:524-5

Ignatius TS Yu, FHKAM (Community Medicine)

Editor-in-Chief, Hong Kong Medical Journal

DOI: $10.12809 / \mathrm{hkmj} 165062$

Six years ago, the Hong Kong Medical Journal (HKMJ) vowed to improve the impact of papers published in the Journal, "We publish not for the sake of publication, but to have an impact on medical practice", by ensuring "that the medical information that we are providing (what we publish) is basically correct and valid".

Greater emphasis was to be placed on methodology to produce valid results. A process of methodological review by clinical epidemiologists for all original articles was introduced. ${ }^{1}$

To improve our capacity to assess the validity of research results, we introduced a series of 12 workshops on Clinical Epidemiology in HKMJ that ran from August 2011 to June 2013 (http://www. hkmj.org/clinical-epidemiology-workshop-series). Their aim was to facilitate authors and reviewers in adopting a more important role in the process of publishing work of a high standard.

The new Editorial Board also introduced a new requirement for original articles to include two boxes of text: 'New Knowledge Added by This Study' and 'Implications for Clinical Practice or Policy.' This was intended to improve and emphasise the potential impact of our published original research papers.

During every Editorial Board meeting, it has been the practice for a number of years to identify papers in each issue of HKMJ that are suitable for continuing medical education (CME). A Senior Editor then works with the authors to prepare questions and answers suitable for CME purposes. We also select papers that may be of public interest and the Editorial Office works with the authors to produce Issue Digests that are released to the local media. These have been widely cited and the impact of local medical research published in HKMJ on improving medical knowledge of the public is now evident.

To further enhance the educational role of HKMJ for doctors and its impact on medical practice, two Senior Editors have taken leading roles to plan and solicit high-quality review papers and contributions to the Medical Practice section. ${ }^{3}$

In August 2012, we introduced the section 'Doctor for Society' to report the activities and achievements of medical doctors who contribute substantially to society on a voluntary basis. We wished to disseminate the message that medical doctors can have a significant impact in the community, outside of their clinic or hospital practice. ${ }^{4}$ The impact has been further extended to the next generation of doctors by engaging medical students from the two local medical schools to interview the nominated interviewee doctors and write a comprehensive report.

In 2013, we began to phase in ahead-of-print versions with DOIs (Online First) for original articles and review articles that had already been accepted and copy-edited. ${ }^{5}$ This has helped to advance the formal release of information available in those articles by months and maximise the impact on medical practice.

Improving accessibility to papers published in HKMJ should help improve its impact. All papers are freely available on the HKMJ website (http:// www.hkmj.org), and the 'mobile website' that was introduced in 2015. This re-styled website is based on 'responsive web' technology that can automatically adjust a website according to the device that is browsing, thus making the content user-friendly and easily accessible. ${ }^{6}$

As a result of open recruitment and invitation, the Editorial Board now has 55 members, including the Editor-in-Chief and five Senior Editors, representing all the 15 Colleges of the Hong Kong Academy of Medicine. This ensures that all aspects of medical and dental practice are adequately covered and impacted by the content in HKMJ.

With the joint efforts of all authors, reviewers, advisors in Biostatistics and Clinical Epidemiology, International Editorial Advisory Board members, Editorial Board members, and the Editorial Office, HKMJ received its first official impact factor in the 2014 version of Journal Citation Reports of Thomson Reuters. The impact factor, however, should not be the only parameter to measure the impact of HKMJ. Papers published in the journal attract much media attention and some local journalists use HKMJ as their prime source to identify new developments in medical practice in Hong Kong. ${ }^{6}$

How much is HKMJ actually influencing medical practice? It will be for you readers to inform us.

The current Editorial Board will be stepping down in mid-December this year, and HKMJ will 
appoint a new Editorial Board under the capable leadership of Prof Martin Wong (currently Senior Editor). He will expand on his vision for the further development of HKMJ in the coming issue.

I would like to close by taking this opportunity to give a big 'Thank You' to all of you! Do not forget to continue your love and support for HKMJ and help the journal to further advance its impact on medical practice!

\section{References}

1. Yu IT. Calling on your continued love and support [editorial]. Hong Kong Med J 2011;17:4.

2. Yu IT. New blood, new initiatives [editorial]. Hong Kong Med J 2011;17:88.

3. Yu IT. Taking stock [editorial]. Hong Kong Med J 2012;18:2.

4. Wong M, Chan KS, Chu LW, Wong TW. Doctor for Society: a corner to showcase exemplary models and promote volunteerism [editorial]. Hong Kong Med J 2012;18:268-9.

5. Yu IT. From strength to strength [editorial]. Hong Kong Med J 2013;19:100.

6. Yu IT. The Third Term [editorial]. Hong Kong Med J 2015;21:4. 